4. Takeda A, Cooper K, Bird A et al. 2010. Recombinant human growth hormone for the treatment of growth disorders in children: a systematic review and economic evaluation. Health technol Assess Winch Engl, 14 (42), 1- 209

5. Bộ y tế. Hướng dẫn chẩn đoán và điều trị một số bểnh thường gặp ở trẻ em. 2015. Nhà xuất bản y hoc. 654-660

6. Rhie. YJ et al. 2019. Long- term safety and effectiveness of growth hormone therapy in Korean children with growth disorders:5- year results of LG growth study. Plos One. 14 (5) 927- 938

7. Nguyễn Thị Hằng. 2019. Nhận xét kêt quả điều tri liêu pháp hormon tái tổ hợp ở bênh nhân thiếu hụt hormon tăng trưởng tại bệnh viên Nhi trung

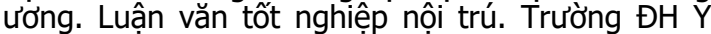
Hà Nội

8. Chatelain $\mathbf{P}$ et al . 2017. A randomized Phase 2 Study of Long - Acting Transcon GH and daily GH in childhood GH deficiency . J Clin Endocrin, 102 (5) 1673- 1682.

9. Hou $L$ et al. 2009. Efficacy and safety of recombinant human growth horrmone solution in children with growth hormone deficiency in China: a multicenter trial. Zhonghua Er Ke Za Zhi Chin J Pedia, 47 (1) 48-52.

\title{
KẾT QUẢ CAI THỞ MÁY CỦA PHƯƠNG THỨC THÔNG KHÍ THÍCH ỨNG Ở BỆNH NHÂN ĐỢT CẤP BỆNH PHỔI TẮC NGHẼN MẠN TÍNH
}

\section{TÓM TẮT}

Muc tiêu: Nhân xét kết quả cai máy của phương thức thông khí thích ứng (AVM) cho bệnh nhân đợt cấp bệnh phổi tắc nghẽn mạn tính. Phương pháp: Nghiên cứu tiến cứu trên 25 bệnh nhân đợt cấp COPD nhập trung tâm Cấp cứu bệnh viện Bạch Mai thông khí xâm nhập đủ điều kiện cai thở máy từ tháng 09/2020 đến tháng 8/2021. Các thông số theo dõi chính như tuổi, giới, các chỉ số khí máu: $\mathrm{pH}, \mathrm{PaCO}_{2}, \mathrm{PaO}_{2}, \mathrm{HCO}_{3}$, $\mathrm{PaO}_{2} / \mathrm{FiO}_{2}$, lactate các thông số lâm sàng: mạch, huyết áp, nhịp thở, $\mathrm{SpO} 2$ được thu thập tại các thời điêm: nhập viện, bắt đâuu cai máy thở bằng $A V M$, sau thở AVM 30 phút, sau 60 phút, sau 120 phút, trước rút ống nội khí quản hoặc trước khi chuyển lại thông khí kiếm soát và sau rút ông nội khí quản. Bênh nhân được đánh giá thành công khi không phải đặt lại nội khí quản sau 48 giờ. Kết quả: Trong số 25 bểnh nhân nghiên cứu (tuổi trung bình 74,04 \pm 9,92 tuối; $8 \%$ nũ giới) cho kết quả có 21 (84\%) bệnh nhân rút ống nội khí quản thành công. Ớ nhóm cai máy thành công, có thời gian cai thở máy $(9,06 \pm 4,5$ giờ) và thời gian nằm ICU $(6,29 \pm 2,61$ ngày), ngắn hơn nhóm thất bại với thời gian cai thớ máy $(16,75 \pm 5,38$ giờ), thời gian nằm ICU $(20,75 \pm 27,58)$ với $p<0,05$. Kết luận: Phương thức AVM có tỷ lệ rút nội khí quản thà̀nh công cao, giúp rút ngắn thời gian thở máy cũng như nằm ICU trên bệnh nhân đợt cấp bệnh phổi tắc nghẽn mạn tính (COPD).

Tư khóa: Thông khí nhân tạo xâm nhâp, AVM, đợt cấp bệnh phổi tắc nghẽn mạn tính, cai thở máy

\section{SUMMARY \\ ADAPTIVE VENTILATION MODE FOR WEANING ON PATIENTS WITH THE}

\footnotetext{
*Bệnh viện đa khoa tỉnh Phú Thọ,

**Bênh viên Bach Mai

Chịu trách nhiệm chính: Nguyễn Đức Lịch

Email: nduclich@gmail.com

Ngày nhân bài: 2.8 .2021

Ngày phản biên khoa hoc: 28.9.2021

Ngày duyệt bài: 5.10 .2021
}

$$
\text { Nguyễn Đức Lịch*, Đỗ Ngọc Sơn** }
$$

\section{EXACERBATION OF CHRONIC}

\section{OBSTRUCTIVE PULMONARY DISEASE}

Objective: To evaluate of weaning results of adaptive ventilation mode (AVM) for patients with the exacerbation of chronic obstructive pulmonary disease (COPD). Methods: A prospective, on 25 invasive ventilated patients due to COPD exacerbations admitted to the Center for Emergency Medicine of Bach Mai Hospital from September 2020 to August 2021. The main variables such as age, sex, blood gas indices: $\mathrm{pH}, \mathrm{PaCO} 2, \mathrm{PaO} 2, \mathrm{HCO} 3, \mathrm{PaO} 2 / \mathrm{FiO} 2$ ratio, lactate, vital signs parameters: heart rate, blood pressure, respiratory rate, $\mathrm{SpO} 2$ were collected at the timelines: admission, 30 minutes, 60 minutes, 120 minutes after AVM, before extubation and after extubation. Patients were considered as successful weaning if they were not be re-intubated after 48 hours. Results: Among 25 patients (mean age 74.04 \pm 9.92 years; $8 \%$ women), there were $21(84 \%)$ patients with successful extubated. In the successful extubation group, weaning time (9,06 $\pm 4,5$ hours) and ICU length of stay (6.29 \pm 2.61 days), shorter than those of failure group (16.75 \pm 5.38 hours), (20.75 \pm 27.58$)$, with $p<0.05$, respectively. Conclusion: The AVM has a higher rate of successful extubation and shorter duration of mechanical ventilation and shorter ICU LOS in patients with exacerbation of chronic obstructive pulmonary disease (COPD).

Keyword: AVM(Adaptive ventilation mode), Exacerbation of COPD, Weaning ventilation.

\section{I. Đă̆T VẤN ĐỀ}

Cai thở máy ở nhóm bệnh nhân đợt cấp bênh phổi tắc nghẽn mạn tính gặp rất nhiều khó khăn do hiện tượng dễ gây căng động phổi quá mức, tăng công thở ${ }^{1,2}$. Nếu không lựa chọn phương thức thích hợp, quá trình cai thở máy dễ dẫn đến thất bại làm tăng nguy cơ tử vong, tàn phế và chi phí điều trị cho bệnh nhân.

Các phương pháp cai thở máy cho bênh nhân đợt cấp COPD hiện nay có chung một nhược 
điểm là mức hỗ trợ không tương xứng với nhu cầu thay đổi liên tục của bệnh nhân, dể dẫn đến mất đồng bộ giữa bệnh nhân và máy thở. Điều này dẫn đến kéo dài thời gian cai thở máy, tăng công sức của nhân viên y tế khi tiến hành cai máy thở cho những bệnh nhân ${ }^{3}$.

AVM với ưu điểm có khả năng tính toán tự động các thông số cơ học phổi, từ đó đưa ra mức hỗ trợ liên tục và phù hợp với từng tình trạng người bệnh. Đồng thời mode thở này cũng giảm thiểu tối đa các thao tác cài đặt cho nhân viên y tế 4 .

\section{II. ĐỐI TƯỢNG VÀ PHƯƠNG PHÁP NGHIÊN CỨU \\ 2.1. Đối tượng nghiên cứu}

Tiêu chuẩn lựa chon: Các bệnh nhân chẩn đoán đợt cấp COPD đắt ống nội khí quản thở máy trên 24 giờ có đủ tiêu chuẩn cai thở máy.

Tiêu chuẩn loại trừ: Có bệnh lý thần kinh cơ tiến triển, bệnh nhân mở khí quản, bệnh nhân không đồng ý tham gia nghiên cứu.

2.2. Thời gian địa điểm nghiên cứu:

Thời gian nghiên cứu: Từ tháng 09/2020 đến tháng 9/2021

Đia điểm nghiên cứu: Trung tâm Cấp Cứu A9, Bệnh viện Bạch Mai.
2.3. Thiết kế nghiên cứu : Nghiên cứu tiến cứu can thiệp

2.4. Cỡ mẫu nghiên cứu: Tất cả bênh nhân nhập viện- Trung tâm cấp cứu $A 9$ trong thời gian nghiên cứu, phù hợp với tiêu chuẩn lựa chọn, có tất cả 25 bệnh nhân.

\subsection{Quá trình thu thập số liệu:}

2.5.1. Tiêu chuẩn đánh giá kêt quả điều trị:

Thành công: không phải đặt lại nội khí quản sau 48 giờ 5 .

Thất bại: phải đặt lại NKQ hoặc tử vong trong vòng 48 sau rút NKQ.

2.5.2. Các bước tiên hành nghiên cứu

Đối tượng nghiên cứu vào viện được hỏi tiền sử, bênh sử, khám lâm sàng để hướng đến chẩn đoán đợt cấp COPD và các dấu hiệu suy hô hấp.

Các thông số về cận lâm sàng: Công thức máu, máu lắng, CRP, sinh hóa máu cơ bản, khí máu động mạch, chụp phim phổi.

Các thông số theo dõi chính bao gồm: Mach, huyết áp, nhịp thở, $\mathrm{SpO}_{2}$, khí máu $\left(\mathrm{pH}, \mathrm{PaO}_{2}\right.$, $\left.\mathrm{PaCO}_{2}, \mathrm{HCO}^{-}\right)$, được thu thập tại các thời điểm: nhâp viện, bắt đâu cai máy thở bằng $\mathrm{AVM}$, sau thở AVM 30 phút, sau 60 phút, sau 120 phút, trước rút ống nội khí quản hoặc trước khi chuyển sang thông khí kiểm soát và sau rút ống nội khí quản.

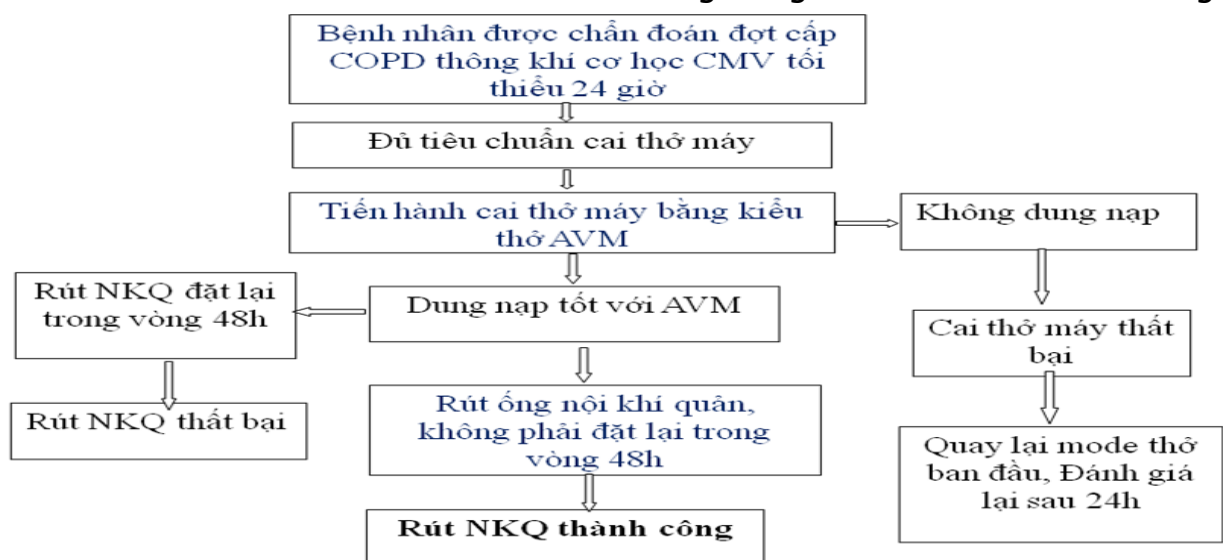

2.6. Phân tích số liệu: Bằng phần mềm thống kê SPSS phiên bản 20, dữ liệu được trình bày dưới dang tần số và tỉ lệ phần trăm với biến định tính, dạng trung bình \pm độ lệch chuẩn hoặc trung vị (tứ phân vị) với biến định lượng. So sánh sự khác biệt giữa các nhóm dùng thuật toán Mann - Whitney $U$ test hoặc $T$ test với biển liên tục và Khi bình phương test bới biến phân loại. Khác biệt có ý nghĩa thống kê khi giá trị kiểm định $\mathrm{p}<0.05$.

\section{KẾT QUẢ NGHIÊN CỨU}

1. Đặc điểm chung của nhóm bệnh nhân nghiên cứu. Tuổi trung bình của nhóm bệnh nhân nghiên cứu là 74,04 $\pm 9,92$ tuổi. Cao nhất là 91 tuổi, thấp nhất 59 tuổi. Số bênh nhân trong nhóm nghiên cứu chủ yếu là trên 65 tuổi.

Đa số bệnh nhân COPD là nam giới. Chỉ có 2 bệnh nhân là nữ giới chiếm $8 \%$.

Bảng 3.1. Tiên sử hút thuốc và bênh tật và các nguyên nhân khởi phát đợt cấp COPD

\begin{tabular}{|c|c|c|}
\hline Tiền sử & Số lượng & Tỷ lệ (\%) \\
\hline Hút thuốc lào, thuốc lá & 23 & 92 \\
\hline Đái tháo đường & 6 & 24 \\
\hline Suy tim & 7 & 28 \\
\hline Tăng huyết áp & 9 & 36 \\
\hline Suy thượng thận & 2 & 8 \\
\hline
\end{tabular}




\begin{tabular}{|c|c|c|}
\hline TBMMN & 1 & 4 \\
\hline Mắc trên 2 bệnh & 7 & 28 \\
\hline Các nguyên nhần gây khởi phát đợt cấp COPD \\
\hline Nguyên nhân & Tần suất (n) & Tỉ lệ (\%) \\
\hline Nhiêm trùng & 19 & 76 \\
\hline Suy tim & 2 & 8 \\
\hline Đột quy não & 1 & 4 \\
\hline Nguyên nhân khác & 3 & 12 \\
\hline
\end{tabular}

Nhận xét: Tỷ lệ bệnh nhân COPD có tiền sử hút thuốc lào, thuốc lá là rất cao, chiếm đa số bệnh nhân trong nhóm nghiên cứu. Các tiền sử bểnh lý thường gặp là: tăng huyết áp, suy tim, đái tháo đường. Khoảng $1 / 3$ số bệnh nhân mắc từ 2 bệnh nền trở lên. Các nguyên nhân thường gặp gây khởi phát đợt cấp COPD là nhiễm khuẩn đường hô hấp, suy tim, đột quy não. Trong đó, nhiễm khuẩn đường hô hẩp gây ra đợt cấp mất bù COPD chiếm tỷ lệ cao nhất.

Bảng 3.2. Đặc điểm cận lâm sàng và lâm sàng của nhóm bệnh nhân khi nhập viện

\begin{tabular}{|c|c|c|c|c|}
\hline \multicolumn{2}{|c|}{ Chỉ số } & Trung bình \pm SD & Thấp nhất & Cao nhất \\
\hline \multirow{9}{*}{$\begin{array}{c}\text { Chỉ số cận lâm } \\
\text { sàng }\end{array}$} & Hông câu( T/I) & $4,1 \pm 0.6$ & 3 & 5,6 \\
\hline & Hemoglobin $(\mathrm{g} / \mathrm{l})$ & $125,1 \pm 19,1$ & 94 & 169 \\
\hline & Bạch câu (G/I) & $12,5 \pm 3,3$ & 8,3 & 19,9 \\
\hline & Procalcitonin (ng/ml) & $6 \pm 16,9$ & 0,4 & 78 \\
\hline & CRPhs(mg/l) & $10,1 \pm 13,1$ & 0,07 & 38 \\
\hline & NT- ProBNP (pmol/l) & $746 \pm 1125,5$ & 9,4 & 4138 \\
\hline & Glucose (mmol/l) & $9,2 \pm 2,7$ & 5,8 & 15 \\
\hline & Natri $(\mathrm{mmol} / \mathrm{l})$ & $137 \pm 4,3$ & 129 & 148 \\
\hline & Kali (mmol/l) & $4,1 \pm 0,5$ & 3,1 & 4,9 \\
\hline \multirow{3}{*}{ Chỉ số lâm sàng } & BMI & $20,11 \pm 3,93$ & 14,6 & 27,6 \\
\hline & Điếm SOFA & $5,6 \pm 2,61$ & 1 & 11 \\
\hline & Điếm APACHE II & $17,19 \pm 4,6$ & 8 & 25 \\
\hline
\end{tabular}

Nhận xét: Các xét nghiệm đánh giá tình trạng nhiếm trùng và suy tim ở mức tương đối cao. Glucose máu lúc vào viện cao hơn mức bình thường. Trong số các bệnh nhân tại thời điểm nhập viện, gặp cả bệnh nhân tăng natri máu và hạ kali máu. Nhóm nghiên cứu có điểm SंOFA và điểm APACHE II ở mức trung bình. Đa phần bệnh nhân có BMI thấp.

Bảng 3.3. Kêt quả khí máu động mạch của nhóm bệnh nhân khi nhập viện

\begin{tabular}{|c|c|c|c|c|c|}
\hline & pH & $\begin{array}{c}\mathrm{PaCO}_{2} \\
(\mathrm{mmHg})\end{array}$ & $\begin{array}{c}\mathrm{PaO}_{2} \\
(\mathrm{mmHg})\end{array}$ & $\begin{array}{c}\mathrm{HCO}_{3}^{-} \\
(\mathrm{mmol} / \mathrm{I})\end{array}$ & $\begin{array}{c}\text { Lactat } \\
(\mathrm{mmol} / \mathrm{L})\end{array}$ \\
\hline Trung bình \pm SD & $7,21 \pm 0,07$ & $82,8 \pm 20,4$ & $114,5 \pm 59,6$ & $32,2 \pm 7,4$ & $3,9 \pm 1,9$ \\
\hline Trung vị & 7,19 & 80 & 98 & 32 & 3,8 \\
\hline Giá trị mode & 7,19 & 109 & 98 & 30 & 2,8 \\
\hline Thấp nhất & 7,11 & 44 & 69 & 20 & 0,8 \\
\hline Cao nhất & 7,33 & 112 & 280 & 50 & 8 \\
\hline
\end{tabular}

Nhận xét: Khí máu lúc nhập viện thể hiện tình trạng toan hô hấp cấp, tăng $\mathrm{CO}_{2}$ máu và giảm oxy máu. Çhỉ số lactat và $\mathrm{HCO}_{3}^{-}$đều cao hơn mức bình thường.

2. Kết quả cai máy của phương thức thông khí thích ứng (AVM) cho bệnh nhân đợt cấp bệnh phổi tắc nghẽn mạn tính

Bảng 3.4. Tỷ lệ rút nội khí quản thành công

\begin{tabular}{|c|c|c|}
\hline & $\begin{array}{c}\text { Số bệnh nhân } \\
(\mathbf{n = 2 5 )}\end{array}$ & $\begin{array}{c}\text { Tỷ lể } \\
(\mathbf{\%})\end{array}$ \\
\hline Thành công & 21 & 84 \\
\hline $\begin{array}{c}\text { Không dung nạp } \\
\text { phương thức thở }\end{array}$ & 3 & 12 \\
\hline Đặt lại NKQ (dưới 48h) & 1 & 4 \\
\hline
\end{tabular}

Nhận xét: 1 bệnh nhân rút nội khí quản thất bại đặt lại sau 1 ngày. Số bệnh nhân rút nội khí quản thành công khi tiến hành cai thở máy bằng phương thức thở AVM chiếm tỉ lê rất cao, chỉ môt số ít bệnh nhân không dung nap phương thức thở, phải chuyển lại phương thức thở ban đầu.
Những bệnh nhân không dung nạp với phương thức thở AVM , không dung nạp với phương thức cai thở máy khác và phải mở khí quản.

Bảng 3.5. Thời gian cai thơ máy bằng kiểu thở AVM và thời gian nằm ICU

\begin{tabular}{|c|c|c|c|}
\hline & $\begin{array}{c}\text { Thành công } \\
(\mathbf{n = 2 1 )}\end{array}$ & $\begin{array}{c}\text { Thất bại } \\
(\mathbf{n = 4 )}\end{array}$ & $\mathbf{p}$ \\
\hline $\begin{array}{c}\text { Số giờ cai thở } \\
\text { máy (Trung } \\
\text { bình } \pm \text { SD) }\end{array}$ & $9,06 \pm 4,5$ & $\begin{array}{c}16,75 \pm \\
5,38\end{array}$ & 0,008 \\
\hline $\begin{array}{c}\text { Số ngày nằm } \\
\text { ICU (Trung } \\
\text { bình } \pm \text { SD) }\end{array}$ & $6,29 \pm 2,61$ & $\begin{array}{c}20,75 \pm \\
27,58\end{array}$ & 0,032 \\
\hline
\end{tabular}

Nhận xét: Nhóm cai thở máy thất bại có thời gian cai thở cao hơn nhiều so với nhóm cai thở máy thành công với khác biệt có ý nghĩa $p<0,05$. 
Nhóm bệnh nhân cai thở máy thành công có thời gian nẳm ICU thấp hơn so với nhóm cai thở máy thất bại với khác biệt có ý nghĩa $p<0,05$.

\section{BÀN LUÂN}

Độ tuổi trung bình của nhóm bệnh nhân nghiên cứu của chúng tôi là 74,04 $\pm 9,92$ tuổi, Nhóm bênh nhân nghiên cứu đa phần là $\geq 65$ tuổi (84\%), độ tuổi cao nhất là 91 tuổi, thấp nhất là 59 tuổi. Cao hơn của tác giả Kiraklí là 64 tuổi (thấp nhất 54 tuổi cao nhất 70 tuổi), và Mohamed là $66,9 \pm 7,8$ tuổi. Tỷ lệ bệnh nhân nam $(92 \%)$ gặp nhiều hơn nữ $(8 \%)$. Tỷ lệ nam trong nghiên cứu của chúng tôi tương đương của tác giả Kirakli ${ }^{6}$ là $90 \%$ và cao hơn của tác giả Mohamed ${ }^{7}$ là $76 \%$.

Trong nghiên cứu của chúng tôi có 9 (36\%) bệnh nhân tăng huyết áp, 7 (28\%) bênh nhân suy tim, 6 (24\%) bệnh nhân đái tháo đường, 2 (8\%) bệnh nhân suy thượng thận, 1 (4\%) bệnh nhân TBMMN. Trong đó có $7(28 \%)$ bệnh nhân mắc từ hai bệnh lý kèm theo trở lên. So với nghiên cứu của Mohamed ${ }^{7}$ có tỷ lệ cao huyết áp và đái tháo đường cao hơn tương ứng là $64 \%$ và $44 \%$.

Khí máu khi nhập viện của nhóm bệnh nhân nghiên cứu thể hiện tình trạng toan hô hấp cấp $(\mathrm{pH} 7,21 \pm 0,07)$, tăng $\mathrm{CO}_{2}$ máu $\left(\mathrm{PaCO}_{2} 82,8 \pm 20,4\right.$ $\mathrm{mmHg}$ ), điều này phù hợp với tính chất của đợt mất bù cấp COPD. Oxy máu trung bình trong giới hạn cho phép $(114,5 \pm 59,6 \mathrm{mmHg})$, chỉ có 3 bểnh nhân có mức $\mathrm{PaO}_{2}$ dưới $80 \mathrm{mmHg}$. Chỉ số $\mathrm{HCO}_{3}{ }^{-}$tăng $(32,2 \pm 7,4 \mathrm{mmol} / \mathrm{l})$, thể hiện tình trạng tăng $\mathrm{CO}_{2}$ mạn tính trong nhiều năm, là đặc điểm đặc trưng của bệnh lý COPD. Chỉ số lactat tăng $(3.9 \pm 1.9 \mathrm{mmol} / \mathrm{l})$ ở những bệnh nhân COPD có thể do quá trình vận động nhe nhàng cũng dễ gây tăng lactat hoặc do thiếu Oxy gây nên. Kết quả này tương đồng với kết quả của Mohamed ${ }^{7}$ khí máu bệnh nhân trước khí đặt nội khí quản $\mathrm{pH}$ $7,25 \pm 0,06, \mathrm{PaCO} 276,42 \pm 17,7 \mathrm{mmHg}, \mathrm{PaO} 2$ $53,7 \pm 19,2 \mathrm{mmHg}, \mathrm{HCO}_{3}{ }^{-39} 3921 \pm 6,8 \mathrm{mmol} / \mathrm{l}$.

Khi tiến hành cai thở máy bằng phương thức thông khí AVM, chúng tôi ghi nhận 21 trường hợp cai thở máy thành công, chiểm $84 \%$, cao hớn của tác giả Kirakli và cộng sự $71,4 \%$, trong số 21 trường hợp này không có bệnh nhân nào phải đặt lại ống nội khí quản trong vòng 48 giờ. Kết quả này cho thây phương thức thông khí có tỷ lệ cai thở máy và rút ống nội khí quản thành công cao ở bệnh nhân COPD có thông khí cơ học.

Trong nghiên cứu của chúng tôi, nhóm cai thở máy thành công có thời gian thở AVM trung bình là $9,06 \pm 4,5$ giờ thấp hơn nghiên cứu tác giả Kirakli và cộng sự , thời gian cai thở máy trung bình 24 giờ, tác giả Mohamed và cộng sự ${ }^{7}$ trung bình là $27,3 \pm 12,3$ giờ. Kết quả này có thể do khác nhau về mức độ nặng của bệnh nhân khi nhập viện: nghiên cứu của tác giả trên được tiến hành trên các bệnh nhân nằm tại các đơn vị hồi sức cấp cứu. Nghiên cứu của chúng tôi cũng cho thấy nhóm thất bại có thời gian cai thở máy cao hơn nhiều $16,75^{ \pm} \pm 5,38$ giờ, cao hơn rất nhiều so với nhóm cai thở máy thành công. Sự khác biệt này cho thấy với bệnh nhân cai thở máy thất bại, ban đầu có sự dung nạp với phương thức thở tuy nhiên càng về sau, có thể do tình trạng mêt cớ, dinh dưỡng kém cùng với các bệnh lý nền phức tạp khác dẫn đến tình trạng cai máy thất bại. Khi tiến hành thống kê thời gian nằm đơn vị ICU tại trung tâm Cấp cứu - bệnh viên Bạch Mai ở 25 bệnh nhân tham gia nghiên cứu, chúng tôi nhận thấy nhóm cai thở máy thành công có thời gian nằm tại tại đơn vị ICU trung bình là $6,29 \pm 2,61$ ngày thấp hơn của tác giả Mohamed và cộng sự là $10,7 \pm 4,2$ ngày, thời gian nằm viện là $15,53 \pm 8,99$ ngày, kết quả nghiên cứu của chúng tôi thấp với tác giả Kirakli với thời gian nằm ICU 11 ngày.

Nghiên cứu của chúng tôi cũng cho thây nhóm thất bại có thời gian nằm ICU và thời gian nằm viện cao hơn nhiêu tương ứng $20,75 \pm 27,58$ ngày và $27,75 \pm 27,5$ ngày, cao hơn rất nhiều so với nhóm cai thở máy thành công. Sự khác biệt này cho thấy sử dụng phương thức thông khí thích ứng giúp giảm thời gian nằm đơn vị ICU và làm giảm thời gian nằm viện cho bệnh nhần.

\section{KẾT LUẬN}

Phương thức AVM cải thiện được các chỉ số lâm sàng, khí máu và rút ngắn thời gian thở máy cũng như nằm ICU trên bệnh nhân đợt cấp bệnh phổi tắc nghẽn mạn tính (COPD).

\section{TÀI LIỆ THAM KHẢO}

1. Barnes PJ. Immunology of asthma and chronic obstructive pulmonary disease. Nat Rev Immunol. 2008;8(3):183-192.

2. Kacmarek RM, Stoller JK, Heuer A. Egan's Fundamentals of Respiratory Care-E-Book. Elsevier Health Sciences; 2016.

3. Nguyễn Đạt Anh (2009). Những Vấn Đề Cơ Bản Trong Thông Khí Nhân Tạo Bản Dịch Tiếng Việt. Nhà Xuất Bản Y Học, Hà Nội.

4. Brunner JX, Iotti GA. Adaptive Support Ventilation (ASV). MINERVA Anestesiol. 2002;68(5):5.

5. MacIntyre NR. Evidence-based guidelines for weaning and discontinuing ventilatory support: a collective task force facilitated by the American College of Chest Physicians; the American Association for Respiratory Care; and the American College of Critical Care Medicine. Chest. 2001;120(6):375S-395S. 
6. Kirakli C, Ozdemir I, Ucar ZZ, Cimen P, Kepil S, Ozkan SA. Adaptive support ventilation for faster weaning in COPD: a randomised controlled trial. Eur Respir J. 2011;38(4):774-780. doi:10.1183/09031936.00081510
7. Mohamed KAE, kamal EI Maraghi S. Role of adaptive support ventilation in weaning of COPD patients. Egypt J Chest Dis Tuberc. 2014;63(2):449-454.

\section{ĐẶC ĐIỂM LÂM SÀNG RỐI LOẠN CHỨC NĂNG TÌNH DỤC Ở NAM BÊNNH NHÂN ĐÁI THÁO ĐƯỜNG TYPE 2 TẠI BÊ̂NH VIỆN BẠCH MAI}

\section{TÓM TẮT}

Đặt vấn đê: Rối loạn chức năng tình dục là một rối loạn thường gặp ở bệnh nhân đái tháo đường type 2. Rổi loạn chức năng tình dục làm suy giảm chất lượng cuộc sống, đăt ra môt thách thức đối với mối quan hệ vợ chồng, ảnh hưởng tới quá trình tuân thủ điều tri của bênh nhân. Mục tiêu nghiên cứu: Mô tả đăc điểm lâm sàng rối loạn chức năng tình dục ở nam bểnh nhân đái tháo đường type 2 . Đối tượng và phương pháp nghiên cứu: Nghiên cứu mổ tả cắt ngang 165 nam bệnh nhân đái tháo đường type 2 điêu trị tại phòng khám Nội tiết - Đái Tháo Đường Khoa khám bệnh - Bệnh viện Bạch Mai từ tháng 08/2020 đến tháng 08/2021. Kết quả: Đối tượng nghiên cứu có độ tuổi trung bình $63,47 \pm 10,14$; nới sinh sống chủ yếu ở thành thị 73,9\%; trình độ học vân cao đẳng, đại học và sau đại học $37,6 \%$, thời gian mắc đái tháo đường trung bình là $8,66 \pm 4,95$ năm, $68,5 \%$ bệnh nhân có rối loạn cương dương, thời gian trung bình có rối loan cương dương là 3,18 $\pm 1,04$ sau khi mắc đái tháo dường; $34,5 \%$ bệnh nhân đánh giá trên thang chất lượng cuộc sống là hòa lấn giữa thỏa mãn và bất mãn. Kết luận: Rối loan chức năng tình dục là một rối loạn thường gặp ở bệnh nhân đái tháo đường type 2 và làm giảm chất lượing cuộc sống của bệnh nhân.

Tư khoá: Đái tháo đường type 2, Rối loạn chức năng tình dục, Đặc điểm lâm sàng.

\section{SUMMARY}

CLINICAL FEATURES OF SEXUAL DYSFUNCTION AMONG MALE PATIENTS WITH TYPE 2 DIABETES IN BACH MAI HOSPITAL

Background: Sexual dysfunction (SD) is one of the common disorders in patients with diabetes. SD affects many aspects such as reducing quality of life, interference with sexual life, problems with partners, increase in stress and poor glycemic control. Objectives: To describe clinical features of Sexual

\footnotetext{
${ }^{1}$ Đai hoc Y Hà Nôi

2Viện sức khỏe Tâm thần, Bênhh viện Bạch Mai Chịu trách nhiệm chính: Nguyễn Thị Phương Email: nguyenphuongpupa@gmail.com Ngày nhận bài: 28.7.2021

Ngày phản biện khoa học: 28.9.2021

Ngày duyệt bài: 5.10 .2021
}

dysfunction in male patients with type 2 diabetes. Subjects and research methods: A cross-sectional descriptive study of 165 patients who were treated at Outpatient Department of Diabetes and Endocrinology, Bach Mai Hospital from August 2020 to August 2021. Results: The study subjects sociademographic characteristics: average age - 63,47 $\pm 10,14$; living in urban areas $-73,9 \%$, The average period of time in which the patients were facing diabetes was 8,66 \pm 4,95 years, Erectile dysfunction was also evident in $68,5 \%$ patients, The mean time of having erectile dysfunction after diabetes was $3.18 \pm 1.04$ years; $34,5 \%$ patients evaluate mixed about equally satisfied and dissatisfied in QoL Score. Conclusion: Sexual dysfunction is extremely common among type 2 diabetic patients and is associated with poorer quality of life.

Keywords: Type 2 Diabetes, Sexual dysfunction, Clinical features.

\section{I. ĐẶT VẤN ĐỀ}

Bê̂nh đái tháo đường (ĐTĐ) là một bệnh chuyển hóa man tính, đặc trưng bởi nồng độ glucose trong máu tăng cao, dẫn đến tổn thương nghiêm trọng đến tim, mạch máu, mắt, thận và thân kinh. Liên đoàn Đái tháo đường thế giới chỉ ra, bệnh ĐTĐ hiện nay có thể coi là một loại bệnh dịch toàn cầu với 415 triệu người trưởng thành bi bênh trên toàn thế giới mắc bênh đái tháo đường, chiếm ( $8,8 \%$ dân số thế giới). Tại Việt Nam, số liệu từ Hội Nội tiết và ĐTĐ (VADE) cho biết, hiện có tới 3,53 triệu người đang "chung sống" với căn bệnh ĐTĐ, và mỗi ngày có ít nhất 80 trường hợp tử vong vì các biến chứng liên quan. Dự báo, số người bắc bệnh có thể tăng lên 6,3 triệu vào năm 2045².

Bệnh ĐTĐ có liên quan đến rối loạn chức năng tình dục (RLCNTD) ở cả nam và nữ. ĐTĐ làm tăng gấp ba lân nguy cơ rối loạn cương dương ở bệnh nhân ĐTĐ so với nam giới không mắc bệnh². Ngoài ra, RLCNTD đặt ra một thách thức đối với mối quan hệ vợ chồng, nó dẫn đến ít sự hài lòng trong hôn nhân, căng thẳng, hạn chế giao tiếp và gây khó khăn trong giải quyết vấn đề, và có thể dẫn đến ly hôn ${ }^{3}$. Hơn nữa, khả năng tự chăm sóc bản thân giảm khi có mâu 